\title{
SISTEM SOSIAL-EKOLOGI MANGROVE DI KABUPATEN TANGERANG
}

\author{
Peggy Ratna Marlianingrum ${ }^{1}$, Luky Adrianto², Tridoyo Kusumastanto ${ }^{3}$ Achmad $^{2}$ \\ Fahrudin $^{4}$
}

\begin{abstract}
${ }^{1}$ Sekolah Pascasarjana Ekonomi Kelautan Tropika, Departemen Ekonomi Sumber Daya dan Lingkungan Institut Pertanian Bogor, STIE Muhammadiyah Jakarta, peggyratna@ymail.com 2,3,4Institut Pertanian Bogor, lukyadrianto@gmail.com; prof.tridoyo@gmail.com
\end{abstract}

\begin{abstract}
ABSTRAK
Penelitian ini bertujuan memformulasikan sistem sosial-ekologi pemanfaatan kawasan ekosistem mangrove di Kabupaten Tangerang. Analisis sosial ekologi ini terkait dengan ketahanan sosial dan ekologis yang dalam konteks ini mencakup mekanisme masyarakat untuk hidup bersama sebagai sebuah komunitas. Pendekatan didasarkan pada kerangka kerja Sistem Sosial Ekologi (SSE) yang merupakan interaksi antara ekosistem mangrove dan sistem sosial di pesisir Kabupaten Tangerang. Metode pengumpulan data untuk memformulasikan sistem sosial-ekologi pemanfaatan ekosistem mangrove yang diperlukan adalah berupa data primer dan data sekunder. Data primer diperoleh melalui observasi lapang habitat ekosistem mangrove di 6 kecamatan pesisir Kabupaten Tangerang. Data sekunder dikumpulkan dari Badan Pusat Statistik (BPS), Dinas Perikanan dan Kelautan, Dinas Kehutanan, Bappeda (Badan Perencanaan Daerah), laporan studi penelitian, dan publikasi ilmiah. Hasil penelitian menunjukkan bahwa sejumlah permasalahan yang bersifat sosial-ekonomi telah mengakibatkan menurunnya luasan mangrove yang berakibat pada turunnya lapangan usaha perikanan. Masalah tersebut meliputi konflik penggunaan lahan, aktivitas ekonomi, deforestasi dan konversi lahan. Permasalahan tersebut dipicu oleh perubahan karakteristik ekosistem, dari yang bersifat maritim ke arah terestrial, yang berdampak pada perubahan pola penghidupan masyarakat. Sejalan dengan perubahan menurunnya luasan mangrove, menyebabkan menurunnya jumlah tangkapan ikan dan pendapatan pemanfaat ekosistem mangrove tersebut. Hasil penelitian difokuskan pada keberadaan ekosistem mangrove berdasarkan aspek sosial, aspek ekonomi, dan aspek lingkungan (ekologi). Optimalisasi pengelolaan ekosistem mangrove yang berkelanjutan dapat meningkatkan kesejahteraan masyarakat pesisir.
\end{abstract}

Kata Kunci: ekonomi kesejahteraan, ekosistem mangrove, sistem sosial-ekologi

\begin{abstract}
This study aims to formulate a socio-ecological system for the utilization of mangrove ecosystem areas in Tangerang Regency. This socio-ecological analysis is related to social and ecological resilience which in this context includes the community's mechanism to live together as a community. The approach is based on the Social Ecological System (SSE) framework which is the interaction between the mangrove ecosystem and the social system on the coast of Tangerang Regency. Data collection methods to formulate the socio-ecological system of mangrove ecosystem utilization required are in the form of primary data and secondary data. Primary data were obtained through field observations of mangrove ecosystem habitats in 6 coastal districts of Tangerang Regency. Secondary data were collected from the Central Statistics Agency (BPS), Fisheries and Marine Service, Forestry Service, Bappeda (Regional Planning Agency), research study reports, and scientific publications. The results of the study indicate that a number of socioeconomic problems have resulted in a decrease in mangrove area which has resulted in a decline in fishery business fields. These problems include land use conflicts, economic activities,
\end{abstract}


deforestation and land conversion. These problems are triggered by changes in ecosystem characteristics, from maritime to terrestrial, which have an impact on changes in people's livelihood patterns. In line with the changes in the decreasing mangrove area, causing a decrease in the number of fish catches and the income of those who use the mangrove ecosystem. The results of the study focused on the existence of the mangrove ecosystem based on social, economic, and environmental (ecological) aspects. Optimizing sustainable management of mangrove ecosystems can improve the welfare of coastal communities.

Keywords: mangrove ecosystem, socio-ecological system, welfare economy

Naskah diterima : 16-08-2021, Naskah dipublikasikan : 28-09-2021

\section{PENDAHULUAN}

Pengelolaan sumberdaya untuk keberlanjutan dari sebuah ekosistem membutuhkan interaksi antara manusia dan alam (ekosistem). Konsep jasa ekosistem berbasis ilmiah dan digunakan untuk kebijakan lingkungan seperti Konvensi Keanekaragaman Hayati/ Convention on Biological Diversity (CBD) dan antar-pemerintah sebagai platform kebijakan lingkungan tentang keanekaragaman hayati dan jasa ekosistem pesisir sebagai penyedia berbagai barang dan jasa ekosistem bagi manusia (Gómez et al 2013). Sebagian besar jasa ekosistem yang diberikan oleh zona pesisir dan laut lebih cepat memburuk daripada ekosistem lainnya. Analisis distribusi populasi menunjukkan bahwa sekitar dua miliar orang tinggal di Indonesia 7,6\% dari luas daratan, dan pesisir Asia telah mengalami tekanan populasi yang sangat tinggi. Hal ini tidak hanya mengarah pada kepadatan populasi yang tinggi tetapi juga pada perkembangan saat ini lebih berada di zona pesisir (UNEP 2008).

Hubungan interaksi antara manusia dan lingkungan perlu dilakukan pendalaman yang lebih baik, agar dapat memberikan manfaat terhadap masyarakat namun juga tidak merusak lingkungannya. Aspek ekologi dan aspek sosial perlu diketahui secara rinci agar pertumbuhan ekonomi untuk mencapai kesejahteraan, tidak membuat kerusakan sumberdaya alam yang dimiliki. Ekosistem mangrove merupakan salah satu sumberdaya pesisir yang dapat mendukung dan memberikan manfaat dalam meningkatkan kesejahteraan masyarakat pesisir. Nilai-nilai tersembunyi dari ekosistem mangrove telah banyak diteliti berdasarkan nilai jasa ekosistem sebagai jasa penyediaan, jasa pendukung, jasa pengaturan dan jasa budaya (Tuan et al. 2012). Costanza et al (2014) mengungkapkan fakta bahwa ekosistem mangrove merupakan salah satu ekosistem yang paling berharga di dunia, namun di satu sisi keberadaannya terancam apabila aktivitas manusia dalam mengejar pertumbuhan ekonomi meningkat. Penelitian ini bermaksud memberikan informasi dalam mempertimbangkan wilayah daratan dan pesisir sebagai satu unit spasial tunggal dalam menilai keakuratan jasa ekosistem mangrove.

Kabupaten Tangerang merupakan salah satu kabupaten di Provinsi Banten yang memiliki potensi sumberdaya mangrove yang cukup besar, namun keberadaannya terancam untuk memperluas area lahan tambak (Muzani 2014). Ekosistem mangrove secara langsung dipengaruhi oleh lahan antropogenik dan kegiatan aktivitas manusia (seperti perikanan, rekreasi dan reklamasi) dan karakteristik sosial (yaitu faktor demografi dan sosial ekonomi) yang akan memberikan dampak pada konservasi dan strategi pengembangan (Koch et al. 2009). Hubungan interaksi antara aspek sosial dan ekologi diperlukan dalam menganalisis nilai jasa ekosistem agar dapat mempertimbangkan kebijakan yang mengarah pada keberlanjutan suatu ekosistem dan kesejahteraan masyarakat pesisir. 


\section{KAJIAN LITERATUR \\ Sistem Sosial Ekologi (SSE)}

Sistem sosial-ekologi (SSE) adalah sistem yang dibentuk dari komponen biologi, geologi, dan fisik (bio-geo-fisik) serta beragam aktor dan institusi sosial terkait dengan komponen-komponen tersebut. Sistem sosial-ekologi sifatnya kompleks dan adaptif serta dibatasi oleh lingkup ruang atau fungsi yang terhubung dengan ekosistem dan konteks masalah tertentu (Berkes et.al 2003, Glaser et al. 2008).

Karakteristik utama SSE diantaranya (Redman et al 2004):

1. Sebuah sistem koheren tersusun dari faktor-faktor biofisik dan sosial yang kerap berinteraksi dalam pola yang resilien dan berkelanjutan;

2. Sebuah sistem yang didefinisikan oleh beberapa skala ruang, waktu, dan organisasi yang saling terhubung dan memiliki hierarki;

3. Kumpulan dari beberapa sumber daya penting (alam, sosioekonomi, dan budaya) dimana aliran dan pemanfaatanya diatur oleh kombinasi dari beberapa sistem ekologi dan sosial; dan

4. Sebuah sistem yang kompleks, dan senantiasa dinamis dengan beradaptasi (Berkes et.al 2003, Machlis et al 1997, Gunderson et al. 2002).

SSE secara sederhana merupakan bentukan dari sistem manusia dan sistem alam yang saling berkaitan dan saling mempengaruhi (Berkes et al. 2000). Keterhubungan ini juga dijabarkan beberapa cendekiawan dalam istilah konsep lain seperti "sistem sosio-ekologi" (socio-ecological system),(Young et al. 2006) "sistem eko-sosisal" (eco-social system) (Krieger 1994), dan "sistem manusia-alam yang tergandeng " (coupled human-environment system) (Turner et al. 2003).

\section{Ekosistem Mangrove}

Ekosistem mangrove merupakan komunitas vegetasi pantai tropis, yang didominasi oleh beberapa spesies pohon mangrove yang mampu tumbuh dan berkembang pada daerah pasang surut pantai berlumpur. Komunitas vegetasi ini umumnya tumbuh pada daerah intertidal dan supratidal yang cukup mendapat aliran air, dan terlindung dari gelombang besar dan arus pasangsurut yang kuat. Kondisi tersebut membuat ekosistem mangrove banyak ditemukan di pantaipantai teluk yang dangkal, estuaria, delta dan daerah pantai yang terlindung (Bengen 2002). Salah satu tipe zonasi ekosistem mangrove di Indonesia, daerah yang paling dekat dengan laut secara umum, sering ditumbuhi Avicennia yang sering kali berasosiasi dengan Sonneratia, jika kondisi lumpurnya kaya bahan organik. Ke arah darat tumbuh Bruguiera cylindrica yang membentuk tegakan-tegakan yang kokoh. Kawasan dibelakang zona garis pantai tumbuh Bruguiera cylindrica bercampur dengan Rizophora apiculata, Rizophora mucronata, Bruguiera parviflora dan Xylocarpus granatum. Kawasan zona paling belakang antara hutan mangrove dengan hutan dataran rendah tumbuh jenis Nypa fruticans, dan pandan laut (Pandanus spp) (Bengen 2002). Ekosistem mangrove sangat dipengaruhi oleh faktor lingkungan di wilayah sekitarnya. Penyebaran dan zonasi mangrove dipengaruhi perbedaan lingkungan yang menyebabkan vegetasi mangrove mempunyai struktur yang khas yaitu dengan membentuk lapisan atau zona vegetasi yang berbeda antara satu dengan yang lainnya (Muhsin dan Indrawati 2008).

Ekosistem mangrove di Indonesia memiliki keanekaragaman jenis yang tertinggi di dunia, seluruhnya tercatat 89 jenis. Beberapa jenis pohon yang banyak dijumpai di wilayah pesisir Indonesia adalah Bakau (Rhizophora. spp.), Api-api (Avicennia spp.), Pedada (Sonneratia spp.), Tanjang (Bruguiera spp.), Nyirih (Xylocarpus spp.), Tenger (Ceriops spp) dan, Buta-buta (Exoecaria spp.) (Kusmana 2002). Jenis-jenis mangrove yang mendominasi di Indonesia antara lain: bakau (Rizophora spp), api-api (Avicennia spp), pedada (Sonneratia spp), tanjang (Bruguiera spp), nyirih (Xylocarpus spp), tengar (Ceriops spp) dan buta-buta (Exocaria spp). Komunitas hutan mangrove yang terbesar di Indonesia tersebut berkaitan dengan sifat dasar lingkungan laut dan iklim tropis Indonesia. Penyebarannya dibatasi oleh letak lintang. Hal ini dikarenakan mangrove sensitif terhadap suhu dingin. Umumnya mangrove akan tumbuh dengan 
baik di daerah yang suhunya pada musim dingin tidak lebih rendah dari $20^{\circ} \mathrm{C}$. Selain itu penyebaran hutan mangrove juga dipengaruhi oleh limpasan air tawar. Terdapat juga jenis-jenis mangrove yang memiliki adaptasi terhadap salinitas yang tinggi, bila tidak ada suplai air tawar akan mempengaruhi kemampuan toleransi mangrove dan biota yang terkait terhadap salinitas (Bengen 2002).

\section{Ekonomi Kesejahteraan}

Ekonomi kesejahteraan adalah sebuah cabang ekonomi yang menggunakan teknik mikroekonomi untuk mengevaluasi kesejahteraan pada tingkat agregat (seluruh ekonomi) (Deardorff 2014). Kesejahteraan punya banyak dimensi, menurut Stiglitz (2017) mengukur kesejahteraan material atau standar hidup dapat berdasarkan:

1. Saat mengevaluasi kesejahteraan material, memperhatikan pendapatan dan konsumsi alih-alih produksi. PDB (Produk Domestik Bruto) adalah ukuran yang paling banyak dipakai untuk melihat aktivitas ekonomi.

2. Menekankan sudut pandang pada rumah tangga.

3. Perhitungan pendapatan dan konsumsi bersama-sama dengan kekayaan, hal ini penting untuk melihat standar hidup.

4. Penekanan yang lebih besar pada distribusi pendapatan, konsumsi dan kekayaan. Nilai pendapatan, konsumsi dan kekayaan rata-rata adalah hitungan statistik yang berguna, namun tidak memberi gambaran keseluruhan tentang standar hidup.

5. Memperluas pengukuran pendapatan pada aktivitas-aktivitas non pasar.

Dimensi kesejahteraan juga dapat diukur berdasarkan :

1. Standar hidup material (pendapatan, konsumsi dan kekayaan)

2. Kesehatan

3. Pendidikan

4. Aktivitas individu termasuk bekerja

5. Suara politik dan tata pemerintahan

6. Hubungan dan kekerabatan sosial

7. Lingkungan hidup (kondisi masa kini dan masa depan)

8. Ketidakamanan, baik yang bersifat ekonomi maupun fisik.

Aspek-aspek lingkungan hidup dari keberlanjutan harus dilakukan kajian terpisah berdasarkan indikator-indikator fisik yang dipilih dengan cermat, dibutuhkan indikator yang jelas pada taraf kerusakan lingkungan yang berbahaya, seperti yang terkait dengan deforestasi mangrove mempengaruhi stock ikan yang berkurang (Stiglitz 2017). Kesejahteraan membahas tentang bagaimana akhirnya kegiatan ekonomi bisa berjalan secara optimal dengan prinsipprinsip keadilan bagi seluruh lapisan masyarakat. Sehingga pembahasannya tidak terlepas dari konteks ilmu sosial. Indikator kesejahteraan hidup seseorang dapat di ukur dengan banyak cara, misalnya dari tingkat hidup masyarakat ditandai oleh terentaskannya kemiskinan, tingkat kesehatan yang lebih baik, perolehan tingkat pendidikan yang lebih tinggi, dan peningkatan produktivitas masyarakat. 


\section{METODE PENELITIAN}

Metode yang digunakan dalam memformulasikan sistem sosial-ekologi pemanfaatan ekosistem mangrove adalah dengan observasi lapang dan analisis data sekunder. Pendekatan didasarkan pada kerangka kerja SSE yang merupakan interaksi antara ekosistem mangrove dan sistem sosial di pesisir Kabupaten Tangerang. Metode pengumpulan data untuk memformulasikan sistem sosial-ekologi pemanfaatan ekosistem mangrove yang diperlukan adalah berupa data primer dan data sekunder. Data primer diperoleh melalui observasi lapang habitat ekosistem mangrove di 6 kecamatan pesisir Kabupaten Tangerang. Data sekunder dikumpulkan dari BPS, Dinas Perikanan dan Kelautan, Dinas Kehutanan, Bappeda (Badan Perencanaan Daerah), laporan studi penelitian, dan publikasi ilmiah.

Metode analisis data sistem sosial ekologi dilakukan berdasarkan data sekunder yang didapat dari berbagai sumber. Secara ekologis, ekosistem mangrove menyediakan jasa ekosistem berupa barang dan jasa yang dihasilkan baik langsung maupun tidak langsung. Hubungan sistem sosial ekologi ekosistem mangrove di Kabupaten Tangerang adalah hubungan proses ekologi lewat jasa ekosistem mangrove (jasa penyediaan, jasa pengaturan, jasa pendukung, jasa budaya) dengan aktivitas sosial ekonomi untuk mencukupi kesejahteraan manusia. Jasa ekosistem ini berinteraksi melalui kegiatan aktivitas manusia dengan ekosistem mangrove seperti perikanan dan rekreasi. Analisis model interaksi ekosistem mangrove dengan sistem sosial seperti terlihat pada Gambar 1.

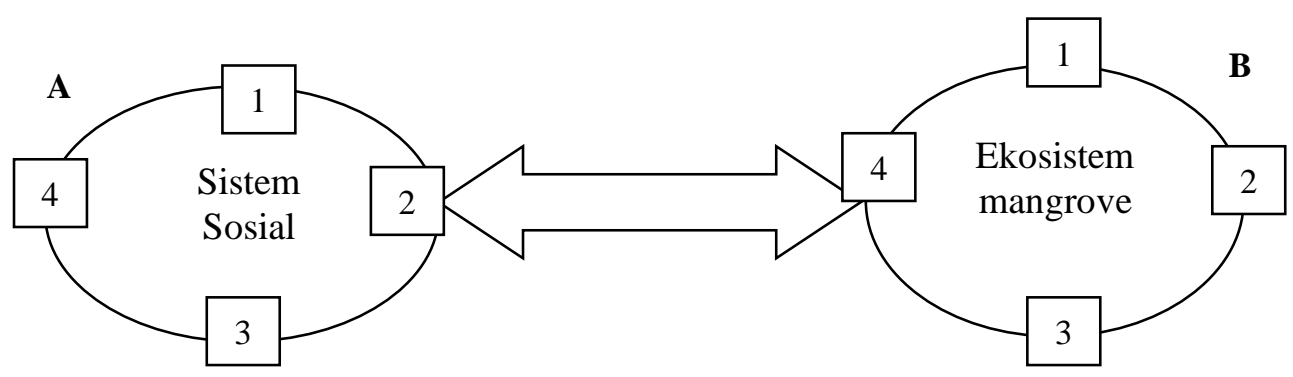

Gambar 1. Analisis Model Interaksi Ekosistem Mangrove dan Sistem Sosial

A

1. Ekonomi

2. Nilai

3.Populasi

4.Teknologi
B

1. Udara

2. Air

3. Tanah

4.Tumbuhan

\section{HASIL DAN PEMBAHASAN}

SISTEM SOSIAL

\section{Letak Geografis, Administrasi dan Batas Wilayah}

Secara geografis, Kabupaten Tangerang terletak di bagian Timur Provinsi Banten dengan titik koordinat antara $106^{\circ} 20^{\prime}-106^{\circ} 43^{\prime}$ Bujur Timur dan $6^{\circ} 00^{\prime}-6^{0} 20^{\prime}$ Lintang Selatan, memiliki total luas wilayah $959,61 \mathrm{~km}^{2}$. Batas-batas wilayah Kabupaten Tangerang secara administratif meliputi: sebelah Utara berbatasan dengan Laut Jawa, sebelah Selatan berbatasan langsung dengan Kabupaten Bogor dan Kota Depok, sebelah Barat berbatasan langsung Kabupaten Serang dan Lebak, dan sebelah Timur berbatasan Provinsi DKI Jakarta dan Kota Tangerang. Secara administrasi wilayah pemerintahan Kabupaten Tangerang membawahi 29 kecamatan, 28 kelurahan dan 246 desa dengan pusat pemerintahan berada di Kecamatan Tigaraksa. Wilayah bagian utara merupakan daerah pesisir pantai sepanjang kurang lebih $50 \mathrm{~km}$. Luas wilayah menurut Kecamatan di Kabupaten Tangerang dapat dilihat pada Tabel 1. 
Tabel 1. Luas wilayah menurut Kecamatan di Kabupaten Tangerang Tahun 2016

\begin{tabular}{cccc}
\hline No. & Kecamatan & $\begin{array}{c}\text { Luas Wilayah } \\
\left(\mathbf{K m}^{\mathbf{2}}\right)\end{array}$ & Keterangan \\
\hline 1 & Mekar Baru & 23,82 & Pesisir \\
2 & K r o n j o & 44,23 & Pesisir \\
3 & K e m i r i & 32,70 & Pesisir \\
4 & M a u k & 51,42 & Pesisir \\
5 & Sukadiri & 24,14 & Pesisir \\
6 & Pakuhaji & 51,87 & Pesisir \\
7 & Teluknaga & 40,58 & Pesisir \\
8 & Kosambi & 29,76 & Pesisir \\
9 & L e g o k & 35,13 & Non pesisir \\
10 & Pagedangan & 45,69 & Non pesisir \\
11 & Cisauk & 27,77 & Non pesisir \\
12 & Pasar Kemis & 25,92 & Non pesisir \\
\hline 13 & Sindang Jaya & 37,15 & Non pesisir \\
14 & Balaraja & 33,56 & Non pesisir \\
15 & Jayanti & 23,89 & Non pesisir \\
16 & Sukamulya & 26,94 & Non pesisir \\
17 & K r e s e k & 25,97 & Non pesisir \\
18 & Gunung Kaler & 29,63 & Non pesisir \\
19 & Cikupa & 42,68 & Non pesisir \\
20 & Panongan & 34,93 & Non pesisir \\
21 & C u r u g & 27,41 & Non pesisir \\
22 & Kelapa Dua & 24,38 & Non pesisir \\
23 & Sepatan Timur & 18,27 & Non pesisir \\
24 & R a j e g & 53,70 & Non pesisir \\
25 & Sepatan & 17,32 & Non pesisir \\
26 & Cisoka & 26,98 & Non pesisir \\
27 & Solear & 29,01 & Non pesisir \\
28 & Tigaraksa & 48,74 & Non pesisir \\
29 & J a m b e & 26,02 & \\
\hline & Jumlah & $\mathbf{9 5 9 , 6 1}$ & \\
\hline
\end{tabular}

Sumber : Kabupaten Tangerang dalam Angka, BPS Tahun 2017

Kabupaten Tangerang membawahi 29 Kecamatan, terdiri 8 kecamatan pesisir dan 21 non pesisir (daratan). Luas terbesar berada di Kecamatan Rajeg yaitu sebesar 5.370 Ha atau 5,60 \% dari luas wilayah Kabupaten Tangerang, sedangkan kecamatan yang memiliki luas terkecil yaitu Kecamatan Sepatan yaitu 1.732 ha atau $1,80 \%$.

Kegiatan penelitian dilakukan di 8 kecamatan pesisir dan 25 desa pesisir yang meliputi daerah keberadaan mangrove. Nama kecamatan dan desa pesisir beserta luas wilayah Kabupaten Tangerang Tahun 2016 seperti tersaji pada Tabel 2. 
Tabel 2. Nama Kecamatan dan Desa Pesisir beserta luas wilayah Kabupaten Tangerang Tahun 2016

\begin{tabular}{|c|c|c|c|}
\hline No & Kecamatan & Desa & Luas Wilayah $\left(\mathrm{km}^{2}\right)$ \\
\hline \multirow[t]{2}{*}{1} & Mekarbaru & Jenggot & 5,82 \\
\hline & & Kedaung & 2,97 \\
\hline \multirow[t]{3}{*}{2} & Kronjo & Kronjo & 6,77 \\
\hline & & Mucung & 7,37 \\
\hline & & Pagedangan Ilir & 7,40 \\
\hline \multirow[t]{3}{*}{3} & Kemiri & Karang Anyar & 4,43 \\
\hline & & Lontar & 7,00 \\
\hline & & Patra Mandala & 6,65 \\
\hline \multirow[t]{4}{*}{4} & Mauk & Ketapang & 4,19 \\
\hline & & Marga Mulya & 5,36 \\
\hline & & Tanjung Anom & 3,62 \\
\hline & & Mauk Barat & 5,52 \\
\hline 5 & Sukadiri & Karang Serang & 3,20 \\
\hline \multirow[t]{4}{*}{6} & Paku Haji & Kohod & 4,40 \\
\hline & & Kramat & 4,63 \\
\hline & & Sukawali & 2,43 \\
\hline & & Surya Bahari & 3,10 \\
\hline \multirow[t]{4}{*}{7} & Teluknaga & Muara & 5,05 \\
\hline & & Tanjung Burung & 8,64 \\
\hline & & Tanjung Pasir & 5,64 \\
\hline & & Lemo & 4,00 \\
\hline \multirow[t]{4}{*}{8} & Kosambi & Salembaran jaya & 6,96 \\
\hline & & Dadap & 4,01 \\
\hline & & Kosambi Timur & 2,88 \\
\hline & & Kosambi Barat & 2,87 \\
\hline
\end{tabular}

Sumber : Kabupaten Tangerang dalam Angka, BPS Tahun 2017

Kecamatan pesisir yang ada di Kabupaten Tangerang memiliki luas wilayah daratan $295,725 \mathrm{~km}^{2}$, memiliki kepadatan penduduk $2.429,85$ jiwa per $\mathrm{km}^{2}$ artinya setiap $1 \mathrm{Km}^{2}$ terdapat 2.430 orang penduduk, dapat dilihat wilayah pesisir ini padat penduduknya, secara rinci luas wilayah, jumlah penduduk dan kepadatan penduduk disajikan pada Tabel 3 Jumlah penduduk di 8 kecamatan pesisir Kabupaten Tangerang mengalami peningkatan dari 691.709 jiwa pada tahun 2015 menjadi berjumlah 718.566 jiwa pada tahun 2016, atau naik sebesar 3,74 persen, terlihat program KB dari pemerintah di 8 kecamatan pesisir ini tidak cukup berhasil. 
Tabel 3. Luas Wilayah, Jumlah Penduduk dan Kepadatan Penduduk setiap Kecamatan Pesisir Tahun 2015-2016

\begin{tabular}{|c|c|c|c|c|c|c|c|}
\hline \multirow[t]{2}{*}{ No } & \multirow[t]{2}{*}{ Kecamatan } & \multicolumn{2}{|c|}{$\begin{array}{l}\text { Luas Wilayah } \\
\qquad\left(\mathrm{Km}^{2}\right)\end{array}$} & \multicolumn{2}{|c|}{$\begin{array}{l}\text { Jumlah Penduduk } \\
\text { (Jiwa) }\end{array}$} & \multicolumn{2}{|c|}{$\begin{array}{l}\text { Kepadatan } \\
\text { Penduduk } \\
\left(\mathrm{Jiwa}_{\left.\mathrm{K} \mathrm{Km}^{2}\right)}\right.\end{array}$} \\
\hline & & 2015 & 2016 & 2015 & 2016 & 2015 & 2016 \\
\hline 1 & Mekarbaru & 23,82 & 27,85 & 36.788 & 36.968 & $1.544,42$ & $1.327,40$ \\
\hline 2 & Kronjo & 44,23 & 45,29 & 57.350 & 56.913 & $1.296,63$ & $1.256,64$ \\
\hline 3 & Kemiri & 32,70 & 32,14 & 42.294 & 42.540 & $1.293,39$ & $1.323,58$ \\
\hline 4 & Mauk & 51,42 & 40,10 & 81.517 & 97.320 & $1.585,32$ & $2.427,24$ \\
\hline 5 & Sukadiri & 24,14 & 21,58 & 55.543 & 55.943 & $2.300,87$ & $2.592,35$ \\
\hline 6 & Paku Haji & 51,87 & 46,02 & 110.928 & 112.459 & $2.138,58$ & $2.443,70$ \\
\hline 7 & Teluknaga & 40,58 & 53,30 & 155.317 & 159.300 & $3.827,43$ & $2.988,74$ \\
\hline \multirow[t]{2}{*}{8} & Kosambi & 29,76 & 29,45 & 151.972 & 157.123 & $5.106,59$ & $5.335,25$ \\
\hline & Jumlah & 298,52 & 295,73 & 691.709 & 718.566 & $2.317,13$ & $2.429,85$ \\
\hline
\end{tabular}

Sumber : BPS Kabupaten Tangerang (2017)

\section{Keragaan Perikanan}

Kegiatan penangkapan ikan terdiri dari penangkapan di daerah tangkapan dekat dan daerah tangkapan jauh Zona Ekonomi Eksklusif (ZEE). Penangkapan laut di perairan terdekat atau di sekitar pulau-pulau di wilayah Kabupaten Tangerang yaitu wilayah Laut Jawa, Selat Sunda, perairan Pulau Panjang, Pulau Pamejan Besar, Pulau Cangkir merupakan wilayah yang berpotensi dalam produksi perikanan. Sedangkan untuk penangkapan ikan di perairan yang jauh dilakukan di perairan wilayah Laut Jawa sampai Selat Karimata. Secara umum kegiatan perikanan dapat diidentifikasi atas empat kegiatan utama yakni, kegiatan perikanan tangkap, kegiatan perikanan budidaya, kegiatan pengolahan dan kegiatan pemasaran hasil perikanan. Kabupaten Tangerang memiliki kegiatan perikanan yang didominasi oleh kegiatan perikanan tangkap, perikanan budidaya dan pemasaran hasil, sedangkan kegiatan pengolahan belum maksimal dilakukan oleh masyarakat. Wilayah pesisir dan laut telah dimanfaatkan oleh masyarakat Tangerang sebagai salah satu sumber bahan makanan utama khususnya protein hewani, penyuluhan gerakan "makan ikan" untuk anak-anak juga kerap dilakukan, terutama di Sekolah Dasar (SD).

Berdasarkan hasil identifikasi data perikanan, produksi perikanan Kabupaten Tangerang tahun 2015 tercatat 40.338,32 ton, di dominasi oleh penangkapan ikan di laut yaitu 20.112,00 ton, budidaya tambak 10.563,60 ton, budidaya laut (keramba ikan) 4.848,00 ton dan yang terendah adalah budidaya kolam $4.814,72$ ton. Produksi perikanan hasil penangkapan ikan laut pada tahun 2016 produksi penangkapan mengalami peningkatan yaitu sebesar $20.449,19$ ton dan produksi budidaya tambak sebesar $11.865,66$ ton. Perbandingan produksi penangkapan ikan laut dan budidaya pada tahun 2015 dan 2016 dapat dilihat pada Tabel 4.

Tabel 4. Produksi Perikanan Kabupaten Tangerang Tahun 2015 dan Tahun 2016

\begin{tabular}{ccccr}
\hline No & Produksi & Satuan & 2015 & \multicolumn{1}{c}{2016} \\
\hline 1 & Penangkapan Ikan Laut & Ton & $20.112,00$ & $20.449,19$ \\
2 & Budidaya Tambak & Ton & $10.563,60$ & $11.865,66$ \\
3 & Budidaya Kolam & Ton & $4.814,72$ & $6.221,09$ \\
4 & Budidaya Laut & Ton & $4.848,00$ & $4.135,79$ \\
\hline & Jumlah & Ton & $40.338,32$ & $42.671,73$ \\
\hline
\end{tabular}

Sumber : Dinas Perikanan dan Kelautan Kabupaten Tangerang, 2017 
Terlihat pada Tabel 4 bahwa pada tahun 2016 produksi perikanan melalui usaha budidaya kolam mencapai $6.221,09$ ton dan melalui usaha budidaya laut mencapai 4.135, 79 ton. Grafik produksi perikanan Kabupaten Tangerang dapat dilihat pada Gambar 2.

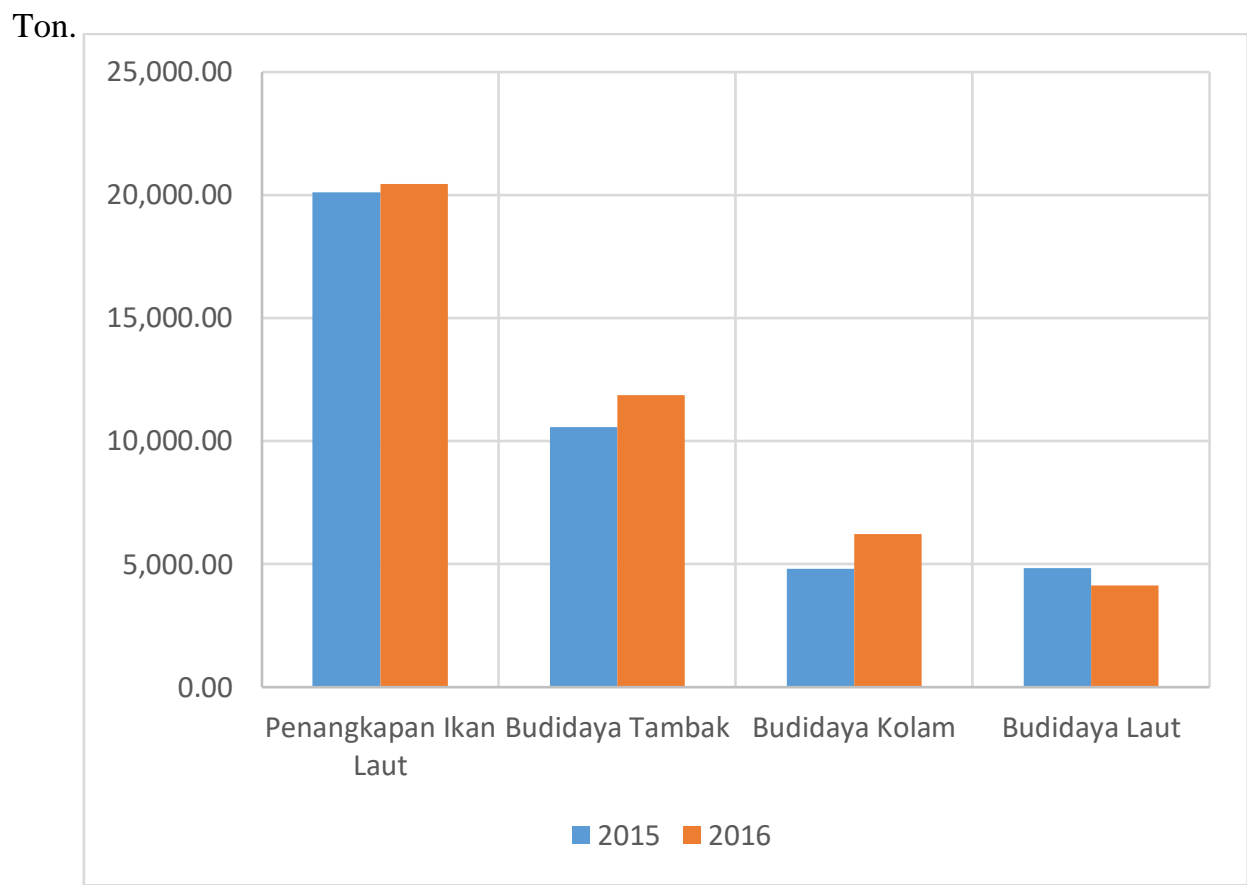

Gambar 2. Grafik Produksi Perikanan Kabupaten Tangerang

Nilai produksi penangkapan ikan laut tahun 2016 senilai Rp. 455.801.600,00 dan budidaya ikan laut Rp. 8.271.580,00. Tingginya nilai produksi ini disebabkan oleh perubahan kurs mata uang (melemahnya nilai tukar rupiah terhadap mata uang asing) terutama mata uang Amerika dan Singapura. Nilai produksi penangkapan ikan laut dan budidaya pada tahun 2015 dan 2016 dapat dilihat pada Tabel 5 dan grafik nilai produksi dapat dilihat pada Gambar 3.

Tabel 5. Nilai Produksi Perikanan Tangkap dan Budidaya Kabupaten Tangerang Tahun 2015 -2016

\begin{tabular}{lllrr}
\hline No & Produksi & Satuan & \multicolumn{1}{c}{2015} & \multicolumn{1}{c}{2016} \\
\hline 1 & Penangkapan Ikan Laut & Rp. & $526.381 .147,00$ & $455.801 .600,00$ \\
2 & Budidaya Tambak & Rp. & $84.508 .800,00$ & $94.925 .280,00$ \\
3 & Budidaya Kolam & Rp. & $68.580 .800,00$ & $89.865 .700,00$ \\
4 & Budidaya Laut & Rp. & $9.696 .000,00$ & $8.271 .580,00$ \\
\hline
\end{tabular}

Sumber : Dinas Perikanan dan Kelautan Kabupaten Tangerang, 2017 


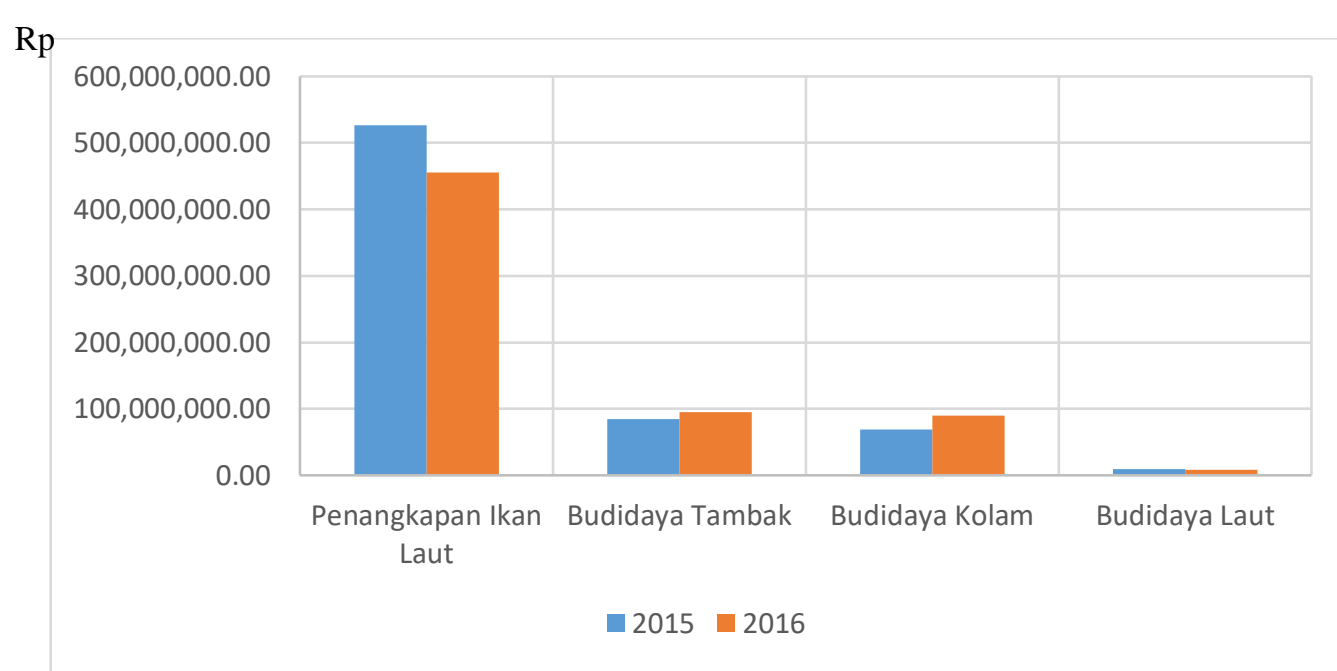

Gambar 3. Grafik Nilai Produksi Perikanan Kabupaten Tangerang

Peluang pengembangan usaha perikanan tangkap sangat terbuka di beberapa kecamatan yang ada di Kabupaten Tangerang, terutama untuk kegiatan penangkapan ikan di perairan di atas 4 mil sampai dengan laut ZEEI. Kegiatan usaha perikanan tangkap akan lebih berkembang lagi jika didukung dengan prasarana dan sarana yang memadai seperti pabrik es, galangan kapal, perikanan, pelabuhan perikanan dan cold storage di beberapa tempat pelelangan ikan (TPI) Kabupaten Tangerang.

\section{SISTEM EKOLOGI}

\section{KARAKTERISTIK EKOSISTEM MANGROVE KABUPATEN TANGERANG}

Mangrove memiliki banyak nilai dan fungsi yang sangat penting bagi ekosistem pesisir dan laut dimana kelangsungan hidup manusia dan pembangunan bergantung kepadanya. Salah satu wilayah pesisir yang mempunyai potensi sumberdaya yang cukup signifikan adalah Kabupaten Tangerang, dengan luas mangrove pada tahun 2017 adalah 415,89 ha. Jenis mangrove yang ditemukan di daerah studi Kabupaten Tangerang memiliki jenis Avicennia sp, Rhiziphora sp dan Sonneratia sp. Spesies mangrove yang teridentifikasi meliputi Avicennia marina, Avicennia alba, Rhizophora mucronata dan Sonneratia caseolaris seperti yang tersaji pada Gambar 4, namun jenis yang paling dominan adalah Rhizopora spp.

Kerapatan mangrove antara 3-23 pohon/ $100 \mathrm{~m}^{2}$ dengan diameter 4,8-38,2 cm (Aida 2015). Mangrove ini tersebar di enam kecamatan pesisir utara Kabupaten Tangerang, yaitu Kecamatan Kronjo, Kecamatan Kosambi, Kecamatan Teluknaga, Kecamatan Paku Haji, Kecamatan Mauk, dan Kecamatan Kemiri. Komposisi mangrove berupa Avicennia alba, Avicennia marina dan Rhizophora mucronata dicirikan dengan sedimen yang di dominasi fraksi pasir dan liat, kerapatan mangrove rata-rata $8-13$ pohon $/ 100 \mathrm{~m}^{2}$. Produksi serasah ekosistem mangrove berdasarkan struktur dan komposisi vegetasi mangrove dan komposisi sedimen memiliki rata-rata produksi serasah sebesar 3,47 $\pm 0,71 \mathrm{~g} / \mathrm{m}^{2} /$ hari. Komposisi komponen penyusun serasah mangrove ini berupa daun, ranting dan buah (Aida 2015). Komposisi jenis mangrove dan berat serasah yang dihasilkan berbeda beda per jenis mangrove paling besar dihasilkan oleh jenis Sonneratia caseolaris sebesar $13.068 \mathrm{~kg} / \mathrm{ha} / \mathrm{th}$. Komposisi jenis mangrove dan berat serasah dapat dilihat pada Tabel 6. 
Tabel 6. Komposisi jenis mangrove dan berat serasah yang dihasilkan per jenis mangrove

\begin{tabular}{clccc}
\multicolumn{5}{c}{ di Kabupaten Tangerang } \\
\hline No & Spesies & $\begin{array}{c}\text { Jumlah } \\
\text { pohon/100m }\end{array}$ & $\begin{array}{c}\text { Persentase } \\
(\%)\end{array}$ & $\begin{array}{c}\text { Serasah } \\
(\mathrm{kg} / \mathrm{ha} / \mathrm{th})\end{array}$ \\
\hline 1 & Avicennia marina & 39 & 67,24 & 124.992 \\
2 & Avicennia alba & 1 & 1,72 & 11.268 \\
3 & Rhizophora mucronate & 15 & 25,86 & 10.350 \\
4 & Sonneratia caseolaris & 3 & 5,17 & 13.068 \\
\hline
\end{tabular}

Sumber : Aida (2015)

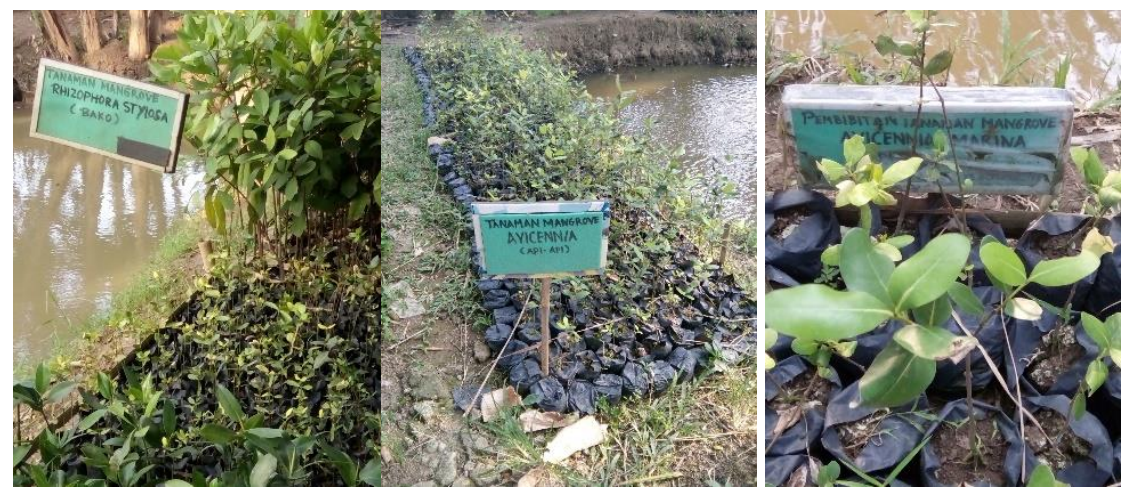

Gambar 4. Jenis mangrove di Kabupaten Tangerang

Masyarakat di sekitar wilayah pesisir Kabupaten Tangerang, telah memanfaatkan ekosistem mangrove sebagai pembibitan mangrove (seperti terlihat pada Gambar 5.2) untuk dijual ke beberapa perusahaan melalui dana CSR (Corporate Social Responsibility). Namun sebagian masyarakat mengonversikan ekosistem mangrove sebagai areal budidaya dan pemukiman. Kesadaran masyarakat Kabupaten Tangerang sejak tahun 2015 sudah mulai membaik tentang pentingnya ekosistem mangrove karena penduduk sekitarnya pernah mengalami abrasi pantai yang cukup jauh dari pinggir pantai dan memberikan kerugian yang cukup signifikan. Namun ada sebagian juga yang masih belum menyadari akan pentingnya ekosistem mangrove, terlihat dari pembuangan sampah rumah tangga ke areal pantai di daerah ekosistem mangrove yang pada akhirnya sampah tersebut mengotori pantai dan laut. Hal tersebut juga akan berakibat pada turunnya ketersediaan sumberdaya ikan karena sampah-sampah tersebut dapat menyebabkan kematian ataupun menghambat pertumbuhan ikan.

Ditinjau dari struktur dan vegetasi, terlihat kondisi mangrove di Kabupaten Tangerang masih cukup baik, dimana hal tersebut ditunjukkan oleh kerapatan pohon dan jumlah jenis pada masing-masing tingkat pertumbuhan. Disamping itu, ekosistem mangrove di areal ini cukup ideal bagi habitat burung air. Kondisi substrat mangrove dominan berupa lumpur dan pasir berlumpur, karena materi (sedimen) pembentuknya dibawa oleh sungai yang mengalir menuju ekosistem mangrove. Kategori jasa ekosistem mangrove di Kabupaten Tangerang terdiri dari jasa penyediaan (provisioning services): nilai tegakan pohon, penyedia bibit mangrove, perikanan mangrove; jasa pengaturan (regulating services): pemecah gelombang (breakwater), penyimpan karbon; jasa pendukung (supporting services): keanekaragaman hayati, tempat pemijahan (spawning ground), dan jasa budaya (cultural services): rekreasi, pendiddikan.

\section{INTERAKSI SISTEM SOSIAL EKOLOGI EKOSISTEM MANGROVE}

Kerangka kerja analisis sistem sosial-ekologi di modifikasi dari penelitian yang telah dilakukan oleh Gilbert and Jansen (1998) disesuaikan berdasarkan bidang minat pada penelitian ini. Sistem sosial-ekologi dikembangkan berdasarkan jasa ekosistem mangrove dalam empat layanan jasa ekosistem yaitu jasa penyediaan, jasa pengaturan, jasa pendukung dan jasa budaya. 
Jasa ekosistem yang ada memberikan manfaat pada masyarakat lokal di sekitarnya yang ikut mendukung kesejahteraan mereka. Hubungan interaksi sosial ekologi dapat digambarkan seperti yang tersaji pada Gambar 5.

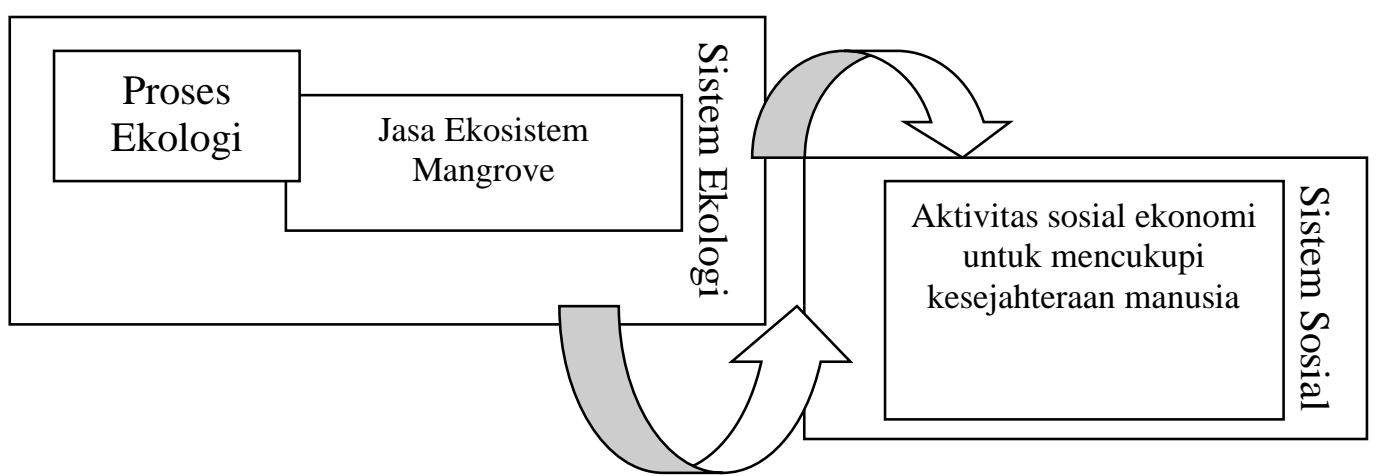

Gambar 5. Hubungan Sistem Sosial Ekologi Ekosistem Mangrove

Identifikasi jasa ekosistem mangrove yang berhubungan langsung digunakan dalam aktivitas sosial ekonomi yaitu penyedia bibit mangrove, dimana para petani bibit mangrove mendapatkan pendapatan/ nilai ekonomi atas penjualan bibit mangrove tersebut. Penangkapan kepiting dan udang sebagai produksi perikanan juga secara langsung memberikan manfaat ekonomi secara langsung kepada para nelayan, dengan jarak penangkapan masih dalam area tidak jauh dari ekosistem mangrove, karena secara ekologi fungsi mangrove sebagai tempat memijah dan berkembang biak. Aktivitas sosial lainnya yang berhubungan dengan ekosistem mangrove yaitu pendidikan dan rekreasi. Ekosistem mangrove memiliki daya tarik tersendiri bagi para pengunjung untuk penelitian maupun para wisatawan, namun kedua aktivitas sosial lainnya tersebut belum berkembang dan dikelola dengan baik.

Hubungan Sistem Sosial Ekologi (SSE) ekosistem mangrove dapat memberikan manfaat sesuai dengan jasa ekosistemnya (jasa penyediaan, jasa pengaturan, jasa pendukung, dan jasa budaya), dengan nilai ekonomi sebesar $\mathrm{Rp}$ 311.524.052.022,64 dengan luasan 415,89 (Marlianingrum et al, 2019). Nilai ekonomi ini dapat ditingkatkan dengan menjaga sistem ekologi ekosistem mangrove, karena pemanfaat ekosistem mangrove dapat terus mendapatkan pendapatan dan dapat meningkatkan kesejahteraan masyarakat pesisir. 


\section{PENUTUP \\ Simpulan}

Ancaman yang dihadapi masyarakat Kabupaten Tangerang adalah penyusutan luas mangrove karena di konversi menjadi tambak, pemukiman, pertanian, dan perkebunan. Sistem sosial-ekologi mangrove di Kabupaten Tangerang saat ini terbentuk oleh adanya empat komponen pembentuk sistem, yaitu: sumberdaya pesisir yaitu ekosistem mangrove yang dimanfaatkan oleh masyakat pesisir karena memiliki jasa ekosistem (jasa penyediaan, jasa pengaturan, jasa pendukung, dan jasa budaya. Kajian SSE ini dapat diketahui bahwa berbagai kegiatan sosial maupun ekonomi masyarakat di wilayah Kabupaten Tangerang sangat tergantung pada keberadaan ekosistem mangrove. Dimensi yang diidentifikasi berdasarkan aspek sosial, aspek ekonomi, dan aspek lingkungan (ekologi).

\section{Saran}

Memberikan kesadaran kepada masyarakat tentang pentingnya SSE ekosistem mangrove dengan cara penyuluhan dimulai dari usia dini sampai dewasa; memasukkan "menjaga habitat lingkungan" pada kurikulum sekolah; peningkatan kapasistas sumberdaya manusia dengan program-program yang disesuaikan dengan kebutuhan; pemerintah atau pun instansi terkait membuat papan petunjuk berisi tulisan sebagai arahan untuk menjaga kualitas habitat mangrove, contoh : "Dilarang membuang sampah disini karena akan membuat mangrove mati", dan sebagainya; pemerintah atau instansi terkait memantau dan memastikan bahwa masyarakat akan mematuhi aturan yang berlaku; masyarakat diberikan latihan untuk mencari mata pencaharian alternatif (seperti pengelolaan buah mangrove yang dijadikan sirup dan kopi); membuat peraturan untuk menjaga kualitas habitat.

\section{UCAPAN TERIMA KASIH}

Penulis mengucapkan terima kasih yang sebesar-besarnya kepada Ketua STIE Muhammadiyah Jakarta dan Rektor IPB University yang telah memberikan dukungan hingga terselesaikannya penelitian ini. Penulis juga mengucapkan terima kasih kepada Kementerian Riset, Teknologi, dan Pendidikan Tinggi RI atas Hibah Penelitian Disertasi Doktor No. 061/KM/PNT/2018.

\section{REFERENSI}

Aida G. R. 2015. Model Dinamik Nilai Ekonomi Ekosistem Mangrove di Wilayah Pesisir Kabupaten Tangerang Provinsi Banten. (Tesis). Bogor (ID) : Institut Pertanian Bogor

Bengen D G. 2002. Sinopsis Ekosistem dan Sumberdaya Alam Pesisir dan Laut serta Prinsip Pengelolaannya. Bogor. Pusat Kajian Sumberdaya Pesisir dan Lautan.

Berkes, F., Colding, J., and Folke, C. 2003. Navigating Social-Ecological Systems: Building Resilience For Complexity And Change. Cambridge University Press, Cambridge, UK.

Berkes, F., Folke, C., \& Colding, J. 2000. Linking social and ecological systems: Management practices and social mechanisms for building resilience, Cambridge University Press.

Costanza, R., R de Groot, P. Sutton, S. van der Ploeg, SJ Anderson, I Kubiszewski, S Farber, and R K Turner. 2014. Changes in the global value of ecosystem services. Global Environmental Change. 26(2014) 152-158

Deardorff, Alan V. (2014), "Welfare economics", Deardorffs' Glossary of International Economics

Glaser, M., Krause, G., Ratter, B., and Welp, M. 2008. Human-Nature-Interaction in the Anthropocene. Potential of Social-Ecological Systems Analysis. 
Gómez Baggethun, E, E. Corbera, and V. Reyes-García. 2013. Traditional Ecological Knowledge And Global Environmental Change: Research Findings And Policy Implications Ecology and Society 18(4): 72.http://dx.doi.org/10.5751/ES. 06288-180472

Gunderson, L. H., and Holling C. S. 2002. Panarchy: understanding transformations in human and natural systems. Island Press, Washington, D.C., USA.

Koch E.W, Barbier E.B, Silliman B.R, Reed D.J, Perillo G. ME, Hacker S.D, Granek E.F, Primavera J.H, Muthiga N, Polasky S., Halpern B.S, Kennedy C.J., Kappel C.V., Wolanski E. 2009. Non-linearity in ecosystem services: temporal and spatial variability in coastal protection. Frontiers in Ecology and the Environment. https://doi.org/10.1890/080126

Kusmana C. 2002. Pengelolaan Ekosistem Mangrove Secara Berkelanjutan dan Berbasis Masyarakat. Jakarta. Makalah disampaikan pada Lokakarya Nasional Pengelolaan Ekosistem Mangrove

Krieger, N., 1994. 'Epidemiology and the web of causation: has anyone seen the spider?', Social Science and Medicine, no.39, pp. 887-903

Marlianingrum P.R, T. Kusumastanto, L Adrianto, A. Fahrudin, Economic analysis of management option for sustainable mangrove ecosystem in Tangerang District, Banten Province, Indonesia, IOP Conf. Ser.: Earth Environ. Sci. 241 (2019) 011001

Machlis, G.E., Force J.E, and. Burch, W.R Jr. 1997. The human ecosystem part I: The human ecosystem as an organizing concept in ecosystem management. Society and Natural Resources, Vol.10, pp.347-367.

Muhsin dan Indrawati. 2008. Keanekaragaman Tumbuhan Air pada Perairan Sungai dan Rawa di Kabupaten Kolaka Provinsi Sulawesi Tenggara. WARKA-WIFTEK 16, pp:5-9.

Muzani. 2014. Optimasi Kelembagaan dalam Pengelolaan Ekosistem Mangrove berbasis Perikanan (Kasus di Kab. Tangerang, Provinsi Banten. (Disertasi). Bogor (ID) : Institut Pertanian Bogor

Redman, C., Grove, M. J. and Kuby, L. 2004. Integrating Social Science into the Long Term Ecological Research (LTER) Network: Social Dimensions of Ecological Change and Ecological Dimensions of Social Change. Ecosystems Vol.7(2), pp. 161-171.

Stiglitz J.E. 2017. The Welfare State In The Twentyfirst Century. Roosevelt Institute. Columbia University

Tuan, V.Q, Kuenzer C, Vo M. Q, Moder F, Oppelt N. 2012. Review of Valuation Methods for Mangrove Ecosystem Services. Ecological Indicators Journal. Elsevier Journal

Turner, Billie Lee, Pamela A. Matson, James J. McCarthy, Robert W. Corell, Lindsey Christensen, Noelle Eckley, Grete K. Hovelsrud-Broda et al. 2003. "Illustrating the coupled human-environment system for vulnerability analysis: three case studies." Proceedings of the National Academy of Sciences 100, no. 14, pp. 8080-85.

United Nations Environment Programme (UNEP). 2008. Ecosystem Service TEEB. Retrieved February 18, 2014, from The Economics of Ecosystems and Biodiversity: http://teebweb.org/resources/ecosystem-services/

Young, O.R., Berkhout, F., Gallopin, G.C. Janssen, M.A., Ostrom, E. \& van der Leeuw, S. 2006. 'The globalization of socio-ecological systems: An agenda for scientific research', Global Environmental Change, vol. 16, no. 3, pp. 304-16. 